\title{
A COMPARISON OF KETOROLAC, DICLOFENAC AND PARACETAMOL FOR POSTOPERATIVE ANALGESIA FOLLOWING ABDOMINAL HYSTERECTOMY
}

\author{
Gaurav Kumar ${ }^{1}$, Lulu Sherif ${ }^{2}$ \\ ${ }_{1}^{1}$ Post Graduate Student, Department of Anesthesiology, Father Muller Medical College and Hospital. \\ ${ }^{2}$ Associate Professor, Department of Anesthesiology, Father Muller Medical College and Hospital.
}

\section{ABSTRACT}

\section{BACKGROUND}

Abdominal hysterectomy is associated with moderate-to-severe postoperative pain. Among non-opioid analgesics diclofenac, paracetamol and ketorolac are most commonly used.

OBJECTIVES: The aim of this study was to compare the analgesic duration, efficacy and side effect profile of paracetamol, diclofenac and ketorolac administered intravenously in patients who underwent abdominal hysterectomy.

\section{METHODS}

In a prospective double-blinded study, in which 90 women undergoing elective abdominal hysterectomy under spinal anesthesia were randomly selected and divided into 3 groups to receive $1 \mathrm{ml}$ (75mg) Diclofenac (Group D), 1ml (30mg) Ketorolac (Group K) and $100 \mathrm{ml}(1000 \mathrm{mg}$ ) Paracetamol (Group P). Two hours post spinal anesthesia, irrespective of completion of surgery study drug was administered intravenously. In post-operative ward analgesic, efficacy was assessed hourly using a visual analog scale (VAS), duration of motor blockade due to spinal anesthesia (Modified Bromage scale), time for rescue analgesia (VAS $>4$ ) were compared and occurrence of adverse effects noted.

\section{STATICS}

Collected data was analyzed using ANOVA.

\section{RESULTS}

The time taken to administer the first dose of rescue analgesic was significantly $(\mathrm{P}<0.05)$ delayed in the group K $(276 \mathrm{mins})$. Overall, mean postoperative VAS scores were significantly better with (Group K) and VAS scores were not significantly different between other (Group P) and (Group D).

\section{CONCLUSION}

Ketorolac was a better post-operative analgesic compared to diclofenac and paracetamol.

\section{KEYWORDS}

Analgesia, Diclofenac, Hysterectomy, Ketorolac, Paracetamol.

HOW TO CITE THIS ARTICLE: Gaurav Kumar, Lulu Sherif. "A Comparison of Ketorolac, Diclofenac and Paracetamol for Postoperative Analgesia following Abdominal Hysterectomy." Journal of Evolution of Medical and Dental Sciences 2015; Vol. 4, Issue 95, November 26; Page: 16017-16020, DOI: 10.14260/jemds/2015/2337.

\section{INTRODUCTION}

Pain in the postoperative period is a critical factor that impedes recovery from surgery and anaesthesia. ${ }^{1}$ Abdominal hysterectomy is associated with moderate-to-severe postoperative pain, which has unfavorable effects on patient's recovery and procedure's outcome. ${ }^{2}$ Effective analgesia is important for early ambulation and postoperative hospital stay, thereby reducing the burden on patient's health and pocket.

Financial or Other, Competing Interest: None.

Submission 16-11-2015, Peer Review 17-11-2015,

Acceptance 18-11-2015, Published 24-11-2015.

Corresponding Author:

Dr. Gaurav Kumar,

Department of Anesthesiology,

Father Muller Medical College,

Mangalore,

Karnataka.

E-mail: gaur27@gmail.com

DOI:10.14260/jemds/2015/2337.
Opioids remains the preferred choice for severe pain; however, the adverse effect of these class of drugs such as nausea, vomiting, sedation and respiratory depression is troublesome. ${ }^{3}$ Non-opioid analgesics (Paracetamol, NSAIDs) are commonly used alone or in combination with opioids for relieving post-operative pain. Among non-opioid analgesics diclofenac, paracetamol and ketorolac are most commonly used. There are enough studies available on post-operative analgesia for surgeries done under general anesthesia, not many for surgeries done under regional anesthesia.

\section{AIMS AND OBJECTIVES}

The aim of this study was to compare the post-operative analgesic duration, efficacy and side effect profile of paracetamol, diclofenac and ketorolac administered intravenously in patients who underwent abdominal hysterectomy under spinal anesthesia with $0.5 \%$ bupivacaine. 


\section{SUBJECTS AND METHODS}

This was a prospective randomized double-blind study in which 90 patients of ASA status 1 or 2 aged between 18-60 years, undergoing elective abdominal hysterectomy under spinal anesthesia in Father Muller Medical College Hospital. Patients with hepatic, cardiac or renal disorder; patients with co-morbid diseases like bronchial asthma, morbidly obese patients; patient whose height $<150 \mathrm{~cm}$ or $>185 \mathrm{~cm}$, contraindication to spinal anesthesia, history of known hypersensitivity to any drugs; patients with history of acid peptic disease and procedures which were converted to general anesthesia and any administration of intraoperative analgesics were also excluded from the study.

After obtaining ethical clearance, 90 patients undergoing total abdominal hysterectomy under spinal anesthesia, satisfying the study criteria were included in the study. A detailed history and preanesthetic evaluation was done on previous day of the surgery. Written informed consent was taken prior to scheduled operation from the patient/patient's party. Patients were randomly allocated using closed envelope technique into 3 groups of 30 each. Group D received $1 \mathrm{ml}$ (75mg) Diclofenac diluted in $100 \mathrm{ml}$ NS. Group K received $1 \mathrm{ml}$ (30mg) Ketorolac diluted in $100 \mathrm{ml}$ NS.

Group P received $100 \mathrm{ml}$ of $(1000 \mathrm{mg})$ Paracetamol. All study drugs were infused intravenously over 20mins. The drug solutions was administered to all patients in a doubleblind manner, whereby neither the person who gave the injections nor the observer who assessed the various parameters was aware of the drug used. Patients involved in the study were premedicated with intravenous $1 \mathrm{mg}$ midazolam. Patients were preloaded with intravenous infusion of Ringer lactate solution $10 \mathrm{ml} \mathrm{kg}$ - 1 over 20 minutes prior to surgery. Patient was shifted to the OT and Pulse oximeter, NIBP and electrocardiography monitors was connected.

For spinal anesthesia $3.5 \mathrm{cc}$ of $0.5 \%$ Bupivacaine is administered by inserting spinal needle at L2-L3 level with patient in left lateral position, under aseptic conditions using a 25G Quincke spinal needle. Time spinal anesthesia given and peak sensory level attained was noted. Achievement of sensory level of at least $\mathrm{T} 6$ was required, if not achieved patients were excluded from the study. Two hours post spinal anesthesia, irrespective of completion of surgery, study drug was administered intravenously over 20 mins. Duration of surgery was noted.
Once the patient was shifted to post-operative ward, sensory block level was noted. Patient's recovery from motor blockade was assessed hourly using modified Bromage score. Severity of pain was assessed hourly using Visual analogue scale (VAS). VAS score $>3$ rescue analgesia $1 \mathrm{mg}$ Butorphanol IV was administered and time noted. This was taken as end point of the study. Throughout the study duration, any side effects caused by the study drug was noted. Collected data analyzed by ANOVA $(\mathrm{p}<0.05)$ was taken to be statistically significant. The statistical software SPSS version 18.0 was used for the analysis of data. Microsoft word and Excel were used to generate graphs and tables.

\section{RESULTS}

Patient's demographic data and duration of surgery are listed in Table 2, which shows that there was no significant difference in both the groups ( $p>0.05)$ with respect to age, height and duration of surgery.

\section{Demographic Data and Duration of Surgery}

\begin{tabular}{|c|c|c|c|c|}
\hline & $\begin{array}{c}\text { Group D } \\
(\mathbf{n}=\mathbf{3 0})\end{array}$ & $\begin{array}{c}\text { Group K } \\
\mathbf{( n = 3 0 )}\end{array}$ & $\begin{array}{c}\text { Group P } \\
\mathbf{( n = 3 0 )}\end{array}$ & $\begin{array}{c}\mathbf{p} \\
\text { Value }\end{array}$ \\
\hline Age & $55.88 \pm 5.16$ & $56.63 \pm 5.99$ & $56.63 \pm 4.33$ & $\begin{array}{c}0.896 \\
\text { NS }\end{array}$ \\
\hline Weight & $58.21 \pm 4.97$ & $59.12 \pm 5.12$ & $57.46 \pm 4.23$ & $\begin{array}{c}0.723 \\
\text { NS }\end{array}$ \\
\hline Height & $159.46 \pm 5.3$ & $159.81 \pm 3.91$ & $158.18 \pm 5.14$ & $\begin{array}{c}0.609 \\
\text { NS }\end{array}$ \\
\hline $\begin{array}{c}\text { Duration } \\
\text { of Surgery }\end{array}$ & $124.0 \pm 13.36$ & $123.1 \pm 10.08$ & $122.3 \pm 13.40$ & $\begin{array}{c}0.933 \\
\text { NS }\end{array}$ \\
\hline \multicolumn{5}{|c|}{ Table 1: Age Distribution among Groups } \\
\hline
\end{tabular}

Bromage Score (Post Op)

\begin{tabular}{|c|c|c|c|c|}
\hline $\begin{array}{c}\text { Time } \\
\text { (mins) }\end{array}$ & $\begin{array}{c}\text { Group D } \\
(\mathbf{n}=\mathbf{3 0})\end{array}$ & $\begin{array}{c}\text { Group K } \\
(\mathbf{n}=\mathbf{3 0})\end{array}$ & $\begin{array}{c}\text { Group P } \\
\mathbf{( n = 3 0 )}\end{array}$ & P Value \\
\hline $\mathbf{0}$ & $2.81 \pm 0.4$ & $2.93 \pm 0.26$ & $2.81 \pm 0.4$ & $\begin{array}{c}0.608 \\
\text { NS }\end{array}$ \\
\hline $\mathbf{6 0}$ & $1.69 \pm 0.70$ & $1.93 \pm 0.26$ & $1.81 \pm 0.403$ & $\begin{array}{c}0.58 \\
\mathrm{NS}\end{array}$ \\
\hline $\mathbf{1 2 0}$ & $0.79 \pm 0.42$ & $0.5 \pm 0.51$ & $0.69 \pm 0.47$ & $\begin{array}{c}0.276 \\
\mathrm{NS}\end{array}$ \\
\hline \multicolumn{5}{|c|}{ Table 2: Bromage Score between the Groups } \\
in Post-Operative Ward \\
\hline
\end{tabular}

Table 2. shows that Bromage score assessed in 3 groups was statistically insignificant $(\mathrm{p}<0.05)$.

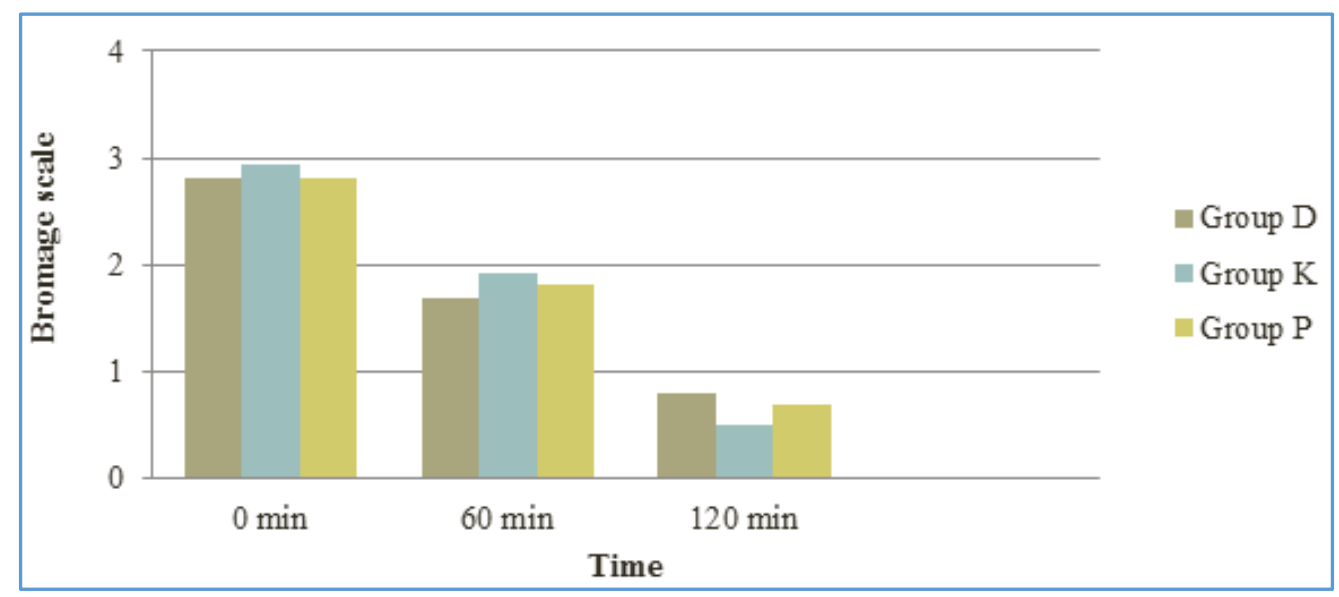

Fig. 1: Bromage Scale among Three Groups 
Visual Analogue Score

\begin{tabular}{|c|c|c|c|c|}
\hline $\begin{array}{l}\text { Time } \\
\text { (mins) }\end{array}$ & $\begin{array}{l}\text { Group D } \\
(n=30)\end{array}$ & $\begin{array}{l}\text { Group K } \\
(n=30)\end{array}$ & $\begin{array}{l}\text { Group P } \\
(n=30)\end{array}$ & $\begin{array}{c}P \\
\text { Value }\end{array}$ \\
\hline $\mathbf{0}$ & $0.25 \pm 0.44$ & 0.00 & $0.19 \pm 0.4$ & $\begin{array}{c}0.119 \\
\text { NS }\end{array}$ \\
\hline 60 & $1.44 \pm 0.62$ & $0.94 \pm 0.25$ & $1.44 \pm 0.51$ & $\begin{array}{c}0.007 \\
\text { Significant }\end{array}$ \\
\hline 120 & $2.31 \pm 0.47$ & $1.88 \pm 0.34$ & $2.25 \pm 0.44$ & $\begin{array}{c}0.16 \\
\text { Significant } \\
\end{array}$ \\
\hline 180 & $3.07 \pm 0.25$ & $2.63 \pm 0.5$ & 3 & $\begin{array}{c}0.02 \\
\text { Significant }\end{array}$ \\
\hline 240 & 0 & 3 & 0 & - \\
\hline 300 & 0 & 3 & 0 & - \\
\hline \multicolumn{5}{|c|}{ Table 3: VAS Score Between the Groups } \\
\hline
\end{tabular}

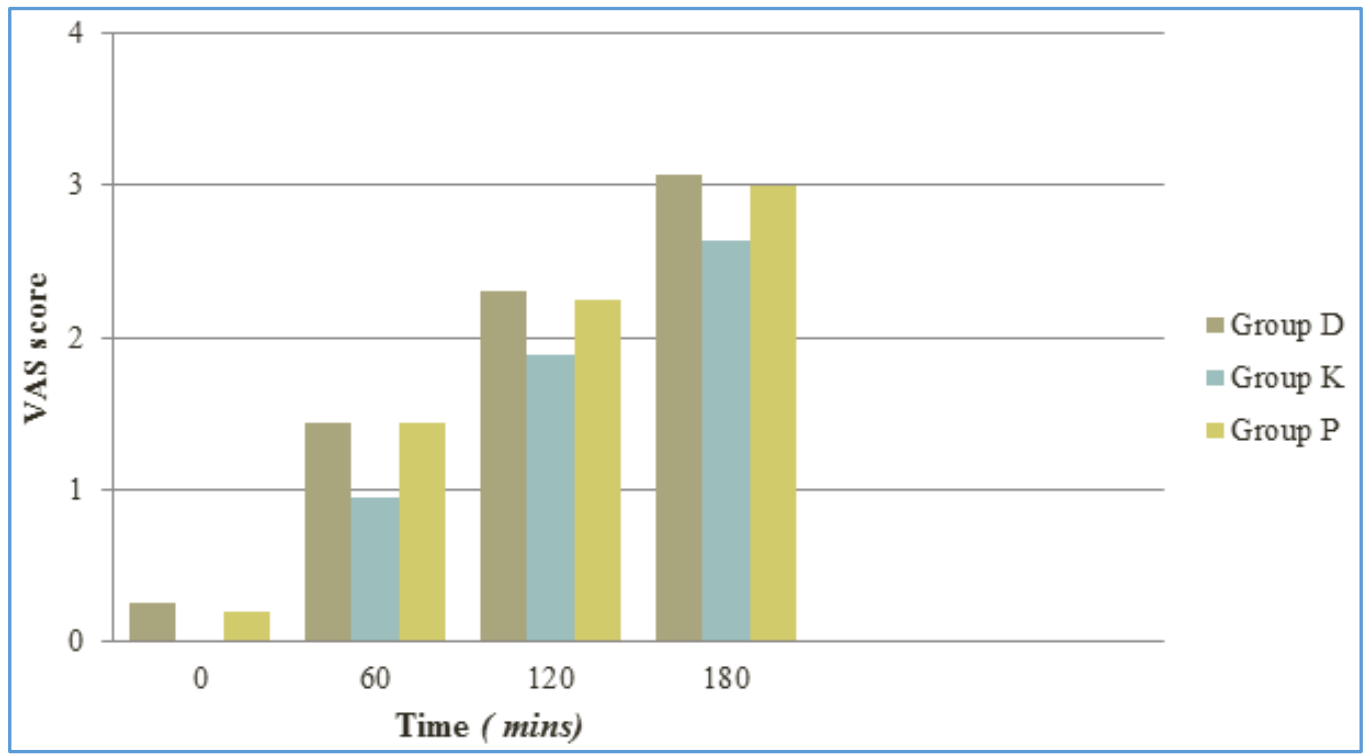

Fig. 2: VAS Score Between the Groups

Overall, mean postoperative VAS scores were significantly $(\mathrm{p}<0.05)$ better with (group $\mathrm{K}$ ) and VAS scores were not significantly different between Group P and Group D (Table 3).

Duration of Analgesia (Time for Rescue Analgesia)

\begin{tabular}{|c|c|c|c|c|}
\hline & $\begin{array}{c}\text { Group } \\
\mathbf{D} \\
(\mathbf{n}=\mathbf{3 0})\end{array}$ & $\begin{array}{c}\text { Group } \\
\mathbf{K} \\
(\mathbf{n}=\mathbf{3 0})\end{array}$ & $\begin{array}{c}\text { Group P } \\
\mathbf{( n = 3 0 )}\end{array}$ & P value \\
\hline $\begin{array}{c}\text { Duration } \\
\text { of } \\
\text { Analgesia }\end{array}$ & $\begin{array}{c}196.6 \pm \\
21.07\end{array}$ & $\begin{array}{c}276.5 \pm \\
15.41\end{array}$ & $\begin{array}{c}202.08 \\
\pm 20.14\end{array}$ & $\begin{array}{c}0.0004 \\
\text { Significant }\end{array}$ \\
\hline \multicolumn{4}{|c|}{ Table 2: Duration of Analgesia Between the Groups } \\
\hline
\end{tabular}

Table 2. shows that the time taken to administer the first dose of rescue analgesic was significantly $(p<0.05)$ delayed in the group K as compared to group D and group P (276 mins for group K, 202 mins for group P and 195 mins for group D). No clinically significant side effects were recorded. The results of this study demonstrate that ketorolac provides effective analgesia in post-operative period after total abdominal hysterectomy. Patients who received a single IV dose of ketorolac experienced pain relief that was superior to diclofenac and paracetamol based on VAS score and time required for rescue analgesia.

\section{DISCUSSION}

Postoperative pain causes marked distress and anxiety and is a major factor that affects recovery from anaesthesia and surgery. Despite major improvements in understanding of acute pain pathophysiology over the past decade, approximately 80 percent of patients undergoing surgical procedures experience mild-to-severe postoperative pain. ${ }^{4}$ In our study, we found that patients who received ketorolac $30 \mathrm{mg}$ IV had significantly better VAS score than the patients who received diclofenac $75 \mathrm{mg}$ IV or paracetamol $1 \mathrm{gm}$ IV. No significant side effects were noted among the groups.

Morrow et al., in their study compared diclofenac and ketorolac for post-operative analgesia after knee arthroscopy found ketorolac to be better than diclofenac. This result matches with our study findings. ${ }^{5}$ Forbes et al., evaluated ketorolac, ibuprofen, paracetamol, and paracetamol-codeine combination in postoperative oral surgery pain, found that ketorolac and ibuprofen both were superior to paracetamol with respect to post-operative analgesia. ${ }^{6}$

In a study conducted by Fredman et al., which compared ketorolac and diclofenac on post-laparoscopic cholecystectomy pain concluded that both ketorolac and diclofenac to be equally effective. 
But in this study, both the drugs were administered intramuscularly compared to our study, administered IV. ${ }^{7}$ From the present study, it can be concluded that ketorolac $30 \mathrm{mg}$ IV showed better analgesic efficacy as compared to diclofenac $75 \mathrm{mg}$ IV and paracetamol $1 \mathrm{gm}$ IV for postoperative pain relief in patients undergoing abdominal hysterectomy under spinal anesthesia without any significant adverse events. However, long-term multicentric trials with more number of patients are required to address these issues further.

\section{BIBLIOGRAPHY}

1. Ng A, Parker J, Toogood L, Cotton BR, Smith G. Does the opioid-sparing effects of rectal diclofenac following total abdominal hysterectomy benefit the patient? $\mathrm{Br} J$ Anaesth 2002; 88: 714-6.

2. Faiz HR, Rahimzadeh P, Visnjevac O, Behzadi B, Ghodraty MR, Nader ND. Intravenous acetaminophen is superior to ketamine for postoperative pain after abdominal hysterectomy: Results of a prospective, randomized, double-blind, multicenter clinical trial. Journal of Pain Research. 2014;7:65-70.
3. Schug SA, Sidebotham DA, McGuinnety M, Thomas J, Fox L. Acetaminophen as an adjunct to morphine by patientcontrolled analgesia in the management of acute postoperative pain. Anesth Analg. 1998; 87(2):368-72.

4. Apfelbaum JL, Chen C, Mehta SS, Gan TJ. Post-operative pain experience: Results from a national survey suggest post-operative pain continues to be undermanaged. Anesth Analg 2003; 97:534-40.

5. Morrow BC, Bunting $\mathrm{H}$ and Milligan K. R. A comparison of diclofenac and ketorolac for postoperative analgesia following day-case arthroscopy of the knee joint. Anaesthesia, 48: 585-587.

6. Forbes JA, Kehm CJ, Grodin CD, Beaver WT. Evaluation of ketorolac, ibuprofen, acetaminophen, and an acetaminophen-codeine combination in postoperative oral surgery pain. Pharmacotherapy. 1990; $10(6$ (Pt 2)):94S105S.

7. Fredman B, Olsfanger D, Jedeikin R. A comparative study of ketorolac and diclofenac on post-laparoscopic cholecystectomy pain. Eur J Anaesthesiol. 1995 Sep; 12(5):501-4. 